\title{
Editorial
}

\section{El Salvador busca un entendimiento nacional}

Bases para el plan de nación, documento elaborado por la Comisión $\mathrm{Na}$ cional de Desarrollo, intenta colocar a El Salvador en un estado de discusión para arribar a entendimientos fundamentales que garanticen su desarrollo sostenible. El documento, que contiene un diagnóstico del estado actual de El Salvador y hace una serie de propuestas para superar sus problemas más graves, entregado al presidente de la república el 16 de enero, pretende estar a la altura de los acuerdos de paz. En continuidad con éstos, retoma la aguda cuestión económico social, dejada de lado durante la negociación del final de la guerra porque, según se explicó en ese entonces, nó era el momento apropiado para discutirla. Concluidos oficialmente los acuerdos, desmilitarizada la sociedad, integrada la antigua guerrilla a la institucionalidad del país y abiertos los espacios indispensables para el debate de los graves problemas nacionales, pareciera que ese momento habría llegado.

Ahora bien, para alcanzar la altura de los acuerdos de paz, Bases para el plan de nación debe ayudar a El Salvador a disminuir la pobreza y encontrar una forma de convivencia humana y humanizadora. Aunque la pretensión es clara, es pronto para darla por hecha. Así como no se puede anticipar su alcance, tampoco se puede negar que, después de la guerra, el documento recoge el reto más importante de El Salvador, el de las necesidades más urgentes de su población. El potencial transformador del planteamiento y las propuestas presentadas obliga a no perder de vista su relación con los acuerdos de paz.

El trabajo de la Comisión Nacional de Desarrollo tiene a su favor el haber recogido e interpretado de manera objetiva y precisa las necesidades más sentidas y las aspiraciones más queridas de prácticamente todos los sectores sociales. Retoma la iniciativa transformadora ahí donde la dejaron los acuerdos de paz y la lanza más allá de las miras estrechas del gobierno y los partidos políticos, abriendo un horizonte social utópico, en cuya construcción todos estamos invitados a participar. 


\section{La importancia del planteamiento}

Bases para un plan de nación es importante por tres razones fundamentales: recoge una antigua aspiración no satisfecha de las fuerzas sociales progresistas salvadoreñas, intenta llenar un vacío proporcionando un instrumento necesario para el buen gobierno de El Salvador y, si es bien aprovechado, puede producir un bien inmenso al pals. Veamos brevemente estas razones.

El futuro de El Salvador no debe quedar abandonado

a lo que los políticos o el capital puedan decidir, según sus

conveniencias, sino que debe incluir las aspiraciones legítimas

de la mayoría de los integrantes de la sociedad.

El documento, en efecto, responde a una antigua aspiración de las fuerzas sociales progresistas del país. Para no ir muy lejos, desde la proclama de la Fuerza Armada de octubre de 1979, ha habido varios intentos importantes para poner las bases de una sociedad más equitativa y solidaria. Ninguno de ellos prosperó por la resistencia férrea al cambio social, calculando equivocadamente que El Salvador podía continuar sin modificar sus estructuras. Al hacerse evidente que el gobierno actual carecía de una dirección clara, prácticamente todos los sectores sociales presentaron propuestas, algunas más consistentes que otras, pero todas ellas preocupadas por orientar a El Salvador hacia la equidad y solidaridad. Bases para un plan de nación ha tomado muy en cuenta todas estas propuestas, enfatizando las coincidencias.

En la medida en que recoge análisis y propuestas ya presentadas y debatidas, su contenido no es novedoso. Su novedad es otra: provenir de una comisión presidencial, en la cual se encuentran representados diferentes sectores importantes del país. Así, no carece de importancia que una comisión presidencial reconozca de manera oficial que el problema principal de El Salvador es la pobreza estructural y sus consecuencias, reflejadas en todos los ámbitos de la vida nacional. El pluralismo de sus miembros acentúa el peso cualitativo de sus conclusiones y sobre todo el haber podido superar la visión particular en aras del interés general. De ahí que sea difícil no estar de acuerdo con el documento. De hecho, hasta ahora, nadie se ha atrevido a rechazarlo o desautorizarlo de manera abierta.

A diferencia de las propuestas anteriores, ésta cuenta con el respaldo que pueda provenir de casa presidencial y, en buena medida, su futuro depende de cuánta fuerza y credibilidad puedan derivarse de esta instancia superior del poder ejecutivo. Aparte de otras consideraciones, este apoyo $\longrightarrow$ la falta del mismo- puede resultar determinante, porque, no obstante que el diag- 
nóstico y la sistematización de las propuestas son inteligibles y abiertos, no se trata de una receta cuyo producto final esté asegurado, sino de un ofrecimiento de posibilidades que deben ser analizadas, apropiadas y ejecuradas. La tarea no es fácil, pues, aparte que las estrategias $y$ acciones concretas casi nunca encuentran un apoyo general, es previsible que el planteamiento enfrente, por un lado, el escepticismo de quienes no han sido escuchados o han sido engañados en diversas ocasiones $y$, por el otro, la resistencia de quienes más deben ceder o sacrificar y que, por la naturaleza del orden social imperante, son los que menos

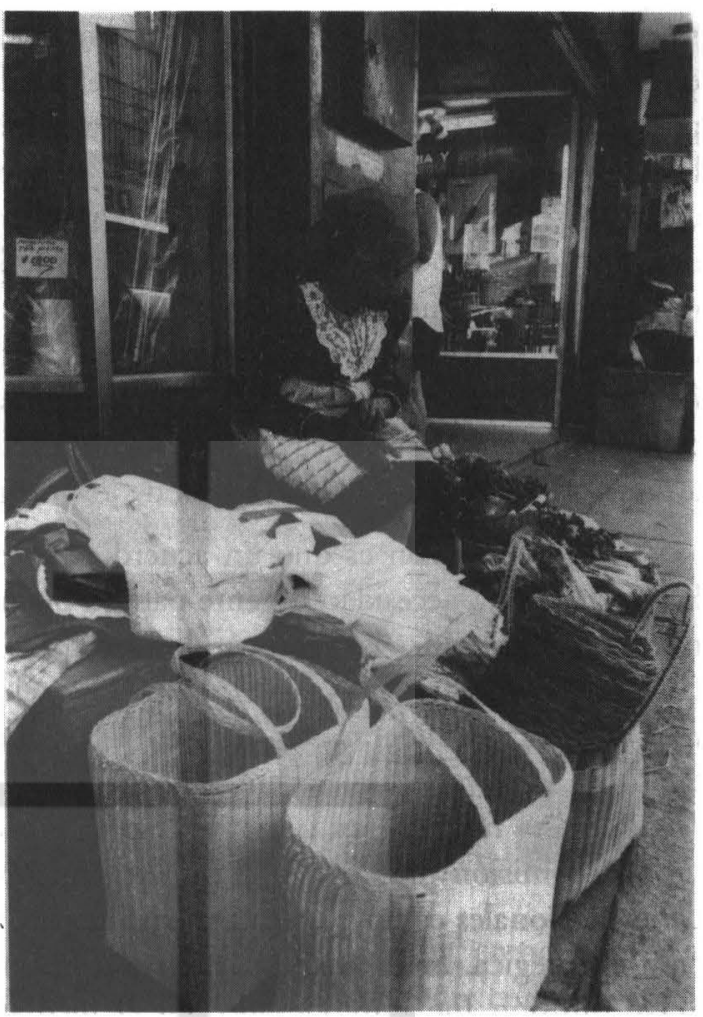
han cedido o sacrificado hasta ahora.

En cuanto Bases para un plan de nación recoge las necesidades y aspiraciones de la mayoría de los salvadoreños con bastante objetividad, ésta puede considerar que ha sido escuchada con atención e interés al menos por una instancia oficiosa. En julio de 1997, según una encuesta del Instituto Universitario de Opinión Pública (IUDOP), un poco más de la mirad de los salvadoreños pedía ser escuchada por el gobierno, aunque sólo cerca del 11 por ciento pensaba en un plan de nación. Así, pues, parecería que el documento también responde a una necesidad sentida desde hace mucho tiempo por el pueblo salvadoreño. Ahora queda por ver si existe disposición y fuerza para impulsar el potencial transformador de las propuestas presentadas.

Al igual que los intentos anteriores, el actual también quiere sentar las bases para una gestión gubernamental no sólo de cara al bien común, sino vinculada a él por medio de un pacto social. Busca un acuerdo nacional, "que sea la base para la formulación de planes y programas de mediano y largo plazo", posibilitando al mismo tiempo "el compromiso y la participación ciudadana", en contraposición a la práctica que prevalecía hasta ahora, más orientada a beneficiar a determinados sectores en detrimento de otros 
mayoritarios. Si este pacto llegara a alcanzarse, la administración estatal no estaría a merced de los caprichós o las veleidades ideológicas de los partidos políticos o los funcionarios electos, cuyos márgenes de acción quedarían limitados a administrar el bienestar de la sociedad. La diferencia vendría dada por el tipo de gestión de la cosa pública que se prometa o haga. El destino del país no estaría sólo en manos de los políticos como hasta este momento, sino que sería, dada su naturaleza, una cuestión social, en cuya configuración participarían, como es debido, todos los sectores sociales. El futuro de El Salvador no debe quedar abandonado a lo que los políticos o el capital puedan decidir, según sus conveniencias, sino que debe incluir las aspiraciones legítimas de la mayoría de los integrantes de la sociedad.

La segunda razón es que un acuerdo básico sobre las prioridades de El Salvador es una necesidad urgente para su buen gobierno. En realidad, identificar esas prioridades y buscar los consensos fundamentales es tarea de cualquier ministerio de planificación. Pero el gobierno actual, cegado por una ideología neoliberal mal digerida y por el esnobismo pensó poder prescindir de la planificación y, en consecuencia, suprimió el ministerio responsable de esta función tan importante para cualquier nación. La designación de una comisión pluralista con carácter nacional para identificar las prioridades nacionales es un reconocimiento tardlo, pero válido de esa equivocación estratégica. Si el precio pagado por el gobierno de Calderón por esta grave omisión fue muy elevado, en el mediano plazo; el próximo podría contar con las ventajas de un plan a partir del cual dirigir el país por el camino de la equidad económica y social.

Concluido el cumplimiento formal de los acuerdos de paz, el gobierno de Calderón careció de ideas para conducir la transición hacia la reforma social. La vanidad política lo perdió. En su afán por distanciarse del gobierno de Cristiani, desaprovechó la experiencia acumulada y lo que pudo haber sido un segundo gobierno de transición, a partir de las líneas esbozadas en los acuerdos de paz, se convirtió en un período de vaivenes e incertidumbre. El gobierno de Calderón no comprendió la importancia de la continuidad en la administración pública y tampoco pudo encontrar cuál debía ser šu aporte específico a la transición de postguerra. Al final de su mandato y en línea con las presiones del Banco Mundial, que piensa que la estabilidad debe estar garantizada por un pacto social, Calderón, reconociendo implícitamente su error, intenta dejar a su sucesor un plan de nación.

Pareciera que la lección ha sido aprendida. El Salvador perdió cinco años que pudieron haber sido aprovechados para fortalecer la institucionalidad, estimular la producción —creando empleo y elevando el ingreso familiary reconstituir las relaciones sociales. El año preelectoral, en lugar de ser un obstáculo, debiera ser un tiempo para reflexionar sobre los errores cometidos, buscando la manera mejor para corregirlosł y para establecer las priori- 
dades de la sociedad, a las cuales el nuevo gobierno deberá atender, independientemente de sus propias ideas e intereses. Un país con los problemas de El Salvador Ino puede permitirse seguir perdiendo tiempo y recursos en empresas o aventuras que lo distraen de sus desafíos reales y más urgentes.

La oportunidad que brinda Bases para un plan de nación, por consiguiente, si es aprovechada, puede producir un bien inmenso al país. Es una oportunidad para formular una propuesta de desarrollo concertada y viable, cuyos frutos podrían verse en el corto y me-

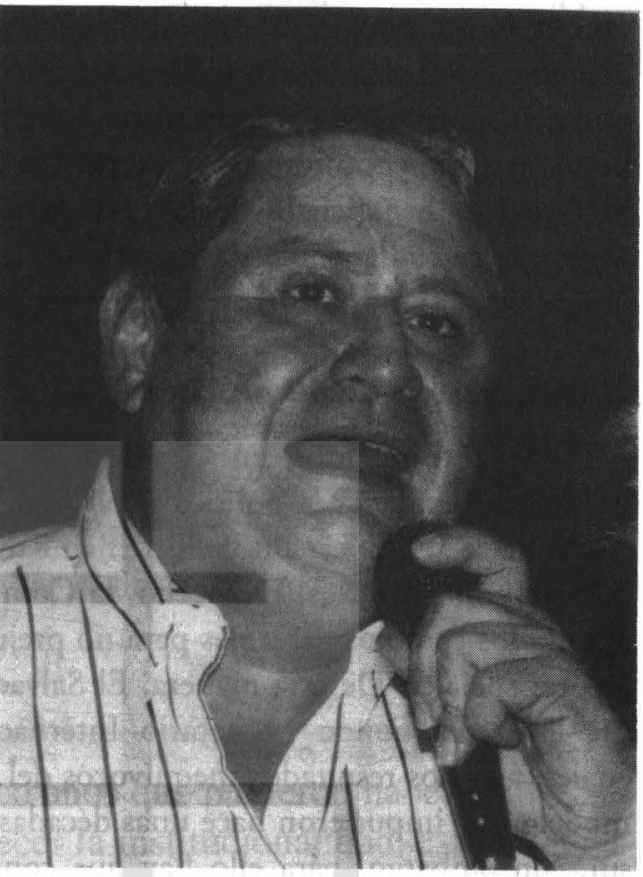

diano plazo. Es una propuesta lo suficientemente abierta como para que nadie se considere excluido, pero también lo suficientemente concreta como para que la discusión no se pierda en vaguedades o irrelevancias. El potencial enorme de esta oportunidad es evidente en la lista de temas sobre los cuales hay que decidir y actuar: ejes del desarrollo, integración productiva de la pequeña y mediana empresa, compromiso del sector financiero, reforma fiscal, estabilidad macroeconómica, apertura económica, relaciones entre capital y trabajo, satisfacción de las necesidades básicas, preservación y gestión del medio ambiente, ordenamiento territorial y gestión urbana, representatividad política, reforma electoral y de los partidos políticos, reordenamiento político y administrativo, rol del Estado, moralidad pública, integración familiar, valores, reforma educativa, ciencia y tecnología, organización y participación ciudadana, responsabilidad ciudadana y profesional, y modernización de la administración pública y del sistema legal.

Concluido el cumplimiento formal de los acuerdos de paz, el gobierno de Calderón careció de ideas para conducir la transición hacia la reforma social.

Al presentar estos temas que, en realidad, son desafíos que el país debe enfrentar, al menos si quiere caminar hacia el desarrollo sostenible, entendido de una forma integral, Bases para el plan de nación, si bien señala con 
una precisión encomiable la problemática que agobia a El Salvador, no se pronuncia por una determinada solución o medida, pero sefiala la dirección que debiera tomarse para garantizar el bien común, sabiendo que ello puede llegar a exigir compromisos y sacrificios importantes para los sectores que más se han beneficiado de la política neoliberal. En esto, el documento muestra una independencia notable de la política gubernamental, no obstante que sus autores fueron nombrados por el presidente de la república.

\section{Distanciamiento del neoliberalismo}

Los planteamientos centrales de Bases para un plan de nación descalifican de manera explícita la política neoliberal y reclaman cambios radicales, incluyendo la modificación del ordenamiento constitucional del Estado, aunque sin concretizarlos. De hecho, la Comisión Nacional de Desarrollo sólo apunta los cambios deseables para no prejuiciar la discusión por parte de los actores sociales. De esta manera, El Salvador se estaría poniendo en la misma línea del Fondo Monetario Internacional y del Banco Mundial, los cuales, ante los resultados inequívocos del neoliberalismo, están revisando el modelo que impusieron hace unas décadas, como alternativa, a los países del sur. Sin embargo, para ello hay que convencer primero a los neoliberales salvadoreños de la necesidad de revisar y modificar la política implantada en algunos aspectos hasta ahora considerados fundamentales. El hecho de que la iniciativa provenga del Banco Mundial o coincida con su planteamiento no debe ser motivo para descartarla sin explorar sus posibilidades para tomar distancia del neoliberalismo, mejorar la calidad de vida de la población y sentar las bases para una transición democrática.

El horizonte desde el cual hay que comprender los planteamientos de Bases para un plan de nación es el bienestar de la sociedad en su conjunto que "esté bien, funcione bien y se sienta bien"-, para lo cual es indispensable satisfacer todas las necesidades básicas, multiplicar y asegurar las opciones actuales y futuras, aprovechar productivamente la energía individual y colectiva, garantizar la seguridad general, crear una nueva cultura de responsabilidad, productividad, solidaridad, tolerancia, humanismo y respeto a las leyes, un territorio limpio y verde, abierto y sin fronteras y promotor de la integración regional. El debate de las propuestas sólo arrojará el resultado esperado si se contextualiza en este horizonte del bienestar social.

Esta insistencia en el bienestar de la sociedad enfatiza una dimensión postergada, si no olvidada, del neoliberalismo, más preocupado por salvaguardar a toda costa los derechos individuales frente a un Estado percibido como una amenaza. No es que se renuncie a la promoción y defensa de aquellos derechos, sino que se busca hacerlos compatibles con la dimensión social de la persona y la realidad. La libertad y el mercado son importantes, pero también lo son los servicios públicos y el bienestar de las mayorías. 
Esta búsqueda de un equilibrio -cuya posibilidad real es muy discutiblelleva a replantear a fondo el papel del Estado como proveedor de tales servicios y garante del bienestar social.

El obstáculo principal que se interpone entre la situación actual y el futuro es la pobreza estructural. Al concebir la pobreza como un mal estructural, los cambios necesarios para erradicarla también deben ser estructurales, es decir, no basta con unas cuantas medidas aisladas y de corta duración, sino que el esfuerzo debe ser continuo, sostenido y radical para ir a los fundamentos de este obstáculo. La comisión presidencial repite algo evidente para una buena parte de la sociedad: El Salvador no se encuentra en el camino del bienestar social y, por consiguiente, tampoco en el del desarrollo sostenible. El crecimiento económico, en el que tanto insisten el gobierno y el sector privado, no es ni puede ser el fin del bienestar que se busca, sino sólo una de sus componentes.

El Salvador perdió cinco años que pudieron haber sido aprovechados para fortalecer la institucionalidad, estimular la producción —creando empleo y elevando el ingreso familiary reconstituir las relaciones sociales.

Por eso, con la delicadeza de quien no desea herir la susceptibilidad del gobierno ni de la empresa privada, se advierte que dicho crecimiento, considerado de manera aislada, "puede llegar" a favorecer el mantenimiento de la pobreza, el deterioro del medio ambiente, el desequilibrio regional y una productividad débil. Quien conoce medianamente la realidad salvadoreña sabe que no hay que esperar para que esas posibilidades se actualicen, porque ya configuran la realidad cotidiana. Hasta ahora, la democratización de El Salvador se ha reducido a mantener el equilibrio macroeconómico sin cambio social. Pero la generalización de la pobreza ha vuelto insostenible el proceso. Por lo tanto, parece no quedar otra alternativa que introducir cambios sociales, conservando el equilibrio macroeconómico.

Es evidente que el desarrollo sólo es sostenible si está estrechamente vinculado a la realidad social del país. Por eso mismo es fundamental contar con una estrategia productiva que defina las áreas prioritarias. Dicho negativamente, la competitividad no puede apoyarse en el bajo costo de la mano de obra y la degradación de los recursos naturales; el país no puede ser tan dependiente de los flujos externos ni tan vulnerable a los vaivenes constantes del mercado mundial -aunque éste, por su propia naturaleza, es inestable y una apertura irrestricta como la que se propone también acarrea estar 
expuesto a sus oscilaciones-; tampoco pueden continuar la incertidumbre ni la dispersión de energías y recursos, perdiendo oportunidades y ventajas.

Dicho positivamente, el sector financiero, el más dinámico y poderoso en la actualidad, debe tomar parte activa en el desarrollo nacional, es decir, sin negarle el derecho al beneficio - aunque debe discutirse el margen-, hay que exigirle de manera simultánea el deber del sacrificio. En concreto, abandonar la perspectiva cortoplacista y adoptar una visión de conjunto y de largo plazo, así como comprometerlo con el desarrollo del país, promoviendo y dirigiendo la inversión. Esto por dos razones, una de carácter moral y la otra nacional. Además de la conservación de la estabilidad y la obtención de ganancia, el sector financiero tiene responsabilidades con la sociedad salvadoreña y su futuro. Desde la perspectiva nacional, se espera que el sector financiero coloque solidariamente el bienestar de los salvadoreños a la cabeza de su lista de prioridades.

El combate contra la pobreza estructural lleva a cuestionar otro elemento fundamental de la ideología neoliberal, el papel del mercado y del Estado. Se reconoce que ambos - y en particular el primero-, aunque necesarios, no pueden absolutizarse $y$, en particular, no se puede esperar que asignen de manera equitativa o manejen de forma eficiente los recursos. Por lo tanto, son necesarios los controles y las restricciones. Son obligaciones del Estado promover el desarrollo económico, a través del establecimiento de reglas y de su aplicación indiscriminada, y garantizar los derechos individuales y sociales - lo cual implica aplicar la ley, prestar servicios básicos y crear condiciones para el mercado-, la seguridad jurídica y la propiedad. Se reconoce así la importancia del Estado, negada por los liberales, en la orientación del crecimiento económico y la distribución de los beneficios.

En este contexto, el documento enfatiza dos aspectos negados por el neoliberalismo salvadoreño, con consecuencias sociales de gran envergadura. Insiste, en primer lugar, en que, por su naturaleza, el Estado está obligado a prestar servicios básicos y, por consiguiente, debe velar de manera directa "para superar los desequilibrios históricos en el acceso de los diversos sectores a bienes y servicios básicos" necesarios para una vida digna. En segundo lugar, subraya que la discusión sobre la propiedad —agrícola — no debe centrarse en su tamaño, sino en los requerimientos para el desarrollo rural. No se trata tanto de imponer una determinada forma de propiedad, ideal para todos, sino de impulsar el desarrollo del ser humano en el ámbito agrícola.

Obviamente, esto está relacionado directamente con la privatización —otro de los elementos claves de la política neoliberal. El documento insinúa la incomparibilidad de la obligación intrínseca del Estado como prestador de servicios públicos y la privatización de éstos. De ahí que pida una discusión en la cual se expliciten tanto las ideas como los intereses económicos y 
políticos de quienes defienden y quienes rechazan la privatización. Mientras esta discusión no se lleve a cabo y sus conclusiones no sean trasladadas al ordenamiento jurídico del pais, las privatizaciones - se advierte- están condenadas a profundizar la polarización existente y a generar incertidumbre en los inversionistas $\mathrm{y}$ ansiedad en los más vulnerables.

La redefinición del Estado pasa por su descentralización, la cual no debe ser entendida únicamente en términos de asignación de recursos y funciones, sino también de la capacidad y el poder para decidir y ejecutar. No se trata sólo de transferir recursos del presupuesto nacional, sino también de modernizar e incrementar la recaudación tributaria municipal. Comprensiblemente, los partidos políticos en general, pero sobre todo el partido que controla el poder ejecurivo, tienen razones suficientes para mostrar reservas ante este planteamiento, porque cuestiona el verticalismo y el autoritarismo con el cual se ejerce el poder en la actualidad. El debate sobre la partida presupuestaria destinada a las alcaldías y el incremento de la tarifa municipal de San Salvador así como la renuencia del poder ejecutivo para aceptar la independencia del poder local son una muestra palpable de esto.

Habría, entonces, que abandonar el concepto reduccionista de modernización, limitado a la estabilidad de unos cuantos índices macroeconómicos, al crecimiento económico de unos pocos y a la privatización de la propiedad estatal y las pensiones. Pocos están en desacuerdo con la búsqueda del bienestar social, aun entendido de manera estructural. La diferencia radical está en que el sector gubernamental y privado piensa que las ideas neoliberales son las más adecuadas para alcanzarlo, negándose a reconocer su fracaso después de casi una década de política neoliberal. A quienes todavía piensan

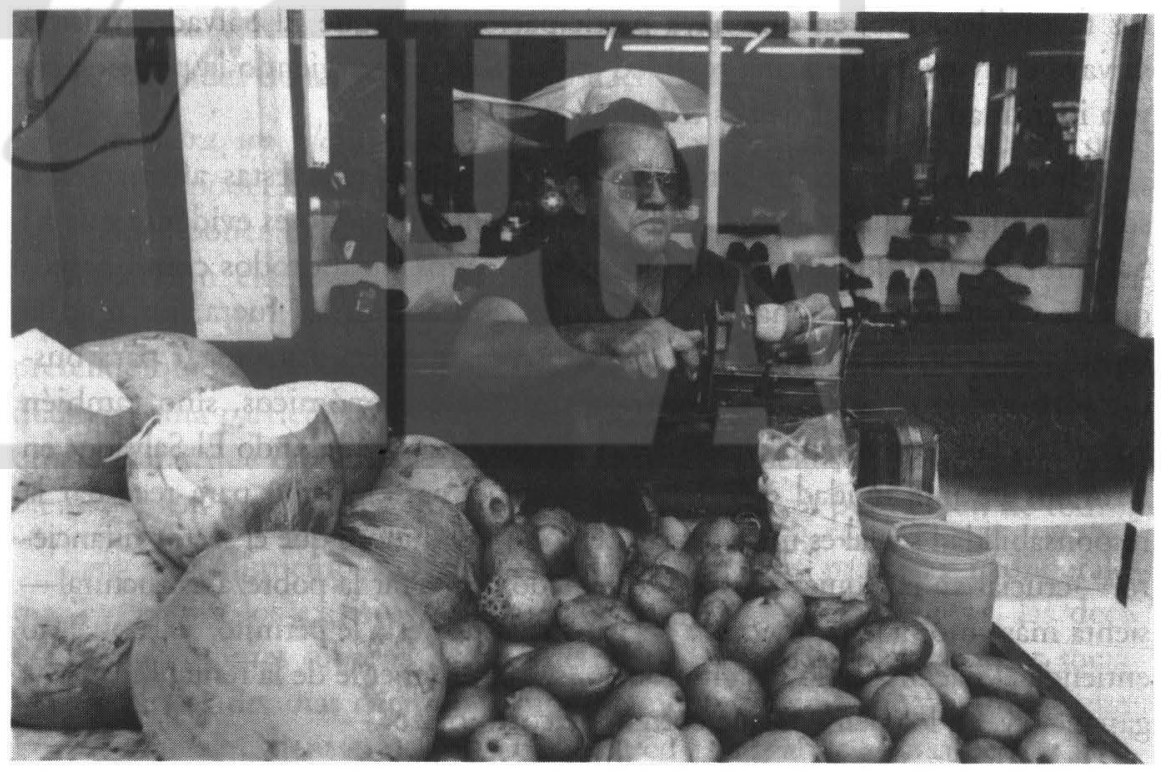


la modernización en términos restringidos, se les recuerda que la guerra civil fue precedida por casi treinta años de crecimiento económico. Si la rigidez del intervencionismo estatal no lleva al bienestar de la sociedad, tampoco el rebalse económico que los neoliberales siguen esperando en vano.

También al sector sindical se le pide un cambio de mentalidad y actitud. En concreto, no considerar ya la empresa como un campo de batalla y colaborar para convertirlo en un espacio para la cooperación y la creatividad. Si los empresarios deben comprometerse con el desarrollo, los trabajadores deben abrirse a la colaboración para construir una armonía respetuosa, en cuyo contexto puedan defender sus intereses económicos. Esto supone, claro está, una actitud similar por parte del empleador. Ambos sectores deben cambiar la mentalidad heredada de las luchas pasadas, para buscar entendimientos de mediano y largo plazo. Desde aquí hay que discutir los intereses de ambos $y$, en concreto, propuestas ambiguas como la flexibilización del mercado de trabajo.

Frente a la visión parcial neoliberal, Bases para el plan de nación enfatiza el desarrollo del país como un proceso integral, es decir, la solidez de los indicadores macroeconómicos debe complementarse con el cambio de las estructuras sociales a favor de las mayorías populares. Para ello, la Comisión Nacional de Desarrollo considera necesario unir en un proyecto común aquello que ya estaba separado, pero que el neoliberalismo ha separado aún más, llegando a extremos intolerables, el muy reducido grupo de quienes se han vuelto más ricos y la inmensa mayoría que lucha contra la pobreza -o simplemente para sobrevivir en ella. Esta unidad singular sólo es posible si los intereses sectoriales quedan sometidos al bien común. Sólo en la medida en que los problemas de la mayoría de los salvadoreños vayan siendo resueltos favorablemente, en que haya participación y en que El Salvador mismo se vaya convirtiendo en una realidad entrañable, irá surgiendo la pertenencia y la identidad nacional de sus habitantes.

Ahora bien, los argumentos en los cuales se apoyan estas afirmaciones son más bien débiles $\mathrm{y}$, hasta cierto punto, ambiguos. No es evidente que $\mathrm{El}$ Salvador sea un todo ni que sea un pais de todos y para todos como parece que la Comisión Nacional de Desarrollo quisiera. Si aś fuera, no tendría sentido que tantos salvadoreños abandonasen su tierra y su hogar para buscar fortuna en el norte. Los contrastes, no sólo económicos, sino también culturales son demasiado chocantes como para seguir pensando El Salvador en términos de una unidad cultural. Insistir en el nacionalismo para recordar la responsabilidad social es importante, pero es muy dudoso que el sector financiero -crucial en cualquier proyecto orientado a superar la pobreza estructuralsienta más amor a la patria que a las ganancias que ésta le permite. El capital no entiende el nacionalismo decimonónico, sino únicamente de la rentabilidad y la ganancia y, en los tiempos que corren, de corto plazo. 
Tampoco es evidente que el destino de El Salvador sea un todo en sí mismo, porque está estrechamente vinculado al de la región e incluso al del resto del mundo. Si, por un lado, la apertura que se propone como una de las mejores alternativas para el desarrollo es contraria al aislamiento y vincula el destino local al global; por otro lado, la viabilidad de la lucha contra la pobreza estructural depende, en buena medida, de la integración de Centroamérica. Siendo consecuentes con la visión de totalidad, los intereses particulares de cada país también debieran someterse a los de la región. De esta manera, la pertenencia y la identidad adquirirán dimensión regional. Lúcida en la mayoría de sus planteamientos, la Comisión Nacional de Desarrollo no pudo superar las ideas nacionalistas del siglo pasado. Además de ser inconsistente con su propio planteamiento sobre la apertura y las realidades regional y mundial, su concepción de nación es peligrosa, pues por ella la sociedad se suele deslizar a extremos inhumanos.

\section{Posibilidades de un entendimiento nacional}

Bases para un plan de nación tiene dos destinatarios, las fuerzas que detentan el poder de decisión y la sociedad. Al entendimiento que se busca para poder poner en marcha las transformaciones propuestas, se llegará por la interacción entre ambos destinatarios, mediados por un grupo gestor, representante de las fuerzas económicas y políticas del país. Con esto se pretende que las decisiones no sean exclusivas de los grupos de poder, sino que haya una participación amplia de la sociedad; pero, al mismo tiempo, se quiere evitar que ésta imponga su parecer sobre aquellos sectores que probablemente son los que más sacrificios tendrán que hacer por el bien de todos.

Este procedimiento supone otra ruptura con las prácticas neoliberales que reservan a los expertos, fundamentalmente a los economistas, las decisiones importantes sobre el destino de un país. Así, las consecuencias sociales y políticas de unas decisiones supuestamente técnicas no son discuridas. Los neoliberales piensan que el saber técnico es superior a la sabiduría polí- 
tica, aparte de considerar que los políticos son, por lo general, ignorantes e ineficientes —en lo cual, lamentablemente, no les falta razón-, pero ello no justifica que las decisiones sean tomadas sólo a partir de consideraciones técnicas. En realidad, esto se hace porque los expertos cuentan con la protección de un presidente o un ministro o de los organismos internacionales multilaterales o de una combinación de los tres. En cualquier caso, estos expertos o técnicos, no obstante tener poder para decidir sobre el füturo de la sociedad, no han sido elegidos por ella ni le dan cuenta de sus acciones.

Contrario a esta práctica común, ahora se intenta promover una participación activa y masiva de la sociedad, recogiendo así la recomendación del Banco Mundial de construir un consenso social amplio sobre el cual apoyar las medidas indispensables para superar la pobreza. El procedimiento, sin embargo, va más allá de la discusión de las propuestas presentadas, pues áboga por una.sociedad organizada, fuerte y estructurada, en la cual los grupos de presión puedan expresar sus intereses. Reconocer, estimular y fomentar la organización y participación social es contrario a la política neoliberal que más bien tiende a desarticular, desconfiar y controlar a la sociedad, en aras de la eficiencia de unas decisiones supuestamente técnicas.

Ahora bien, para tranquilizar a los neoliberales se insiste en la necesidad de un equilibrio entre derechos y deberes. Por un lado, se garantiza la plenitud de los derechos establecidos por la ley y, por el otro, se exige el cumplimiento indiscriminado de los deberes impuestos por la misma ley. No se puede dar por sentado que la prevención contra quienes piensan que para estar bien es necesario imponer exigencias y demandas exhorbitantes, olvidando los deberes, está dirigida únicamente a los sectores populares, porque los grupos de poder piensan de la misma manera. La diferencia radica en que estos últimos plantean sus demandas y exigencias a través de canales exclusivos con las altas esferas del poder político, y cuando no son escuchados en la forma esperada, presionan e incluso amenazan. Por lo tanto, el desafío de rescatar la responsabilidad ciudadana, modificando la mentalidad, la actitud y los valores, para pensar en el bien del país por encirna de intereses sectoriales o grupales, es para todos.

No obstante lo anterior, la participación de la sociedad, organizada y no organizada, en este esfuerzo también debiera caracterizarse por la responsabilidad. El peso específico de las críticas o propuestas no viene dado sólo por la cantidad de la mayoría, sino que además está determinado por su cualificación. El aporte de la sociedad, cómo cualquier otro, debe ser racional. Para ello aquélla debe estar bien informada, reflexionar y proponer de forma creativa. Todo ello sin perder la perspectiva de las mayorías populares. Dicho con otras palabras participar implica responsabilidad: defender los intereses mayoritarios al mismo tiempo que se construye el bien común de los salvadoreńos. 
Reconocer, estimular y fomentar la organización y participación social es contrario a la política neoliberal que más bien tiende a desarticular, desconfiar y controlar a la sociedad, en aras de la eficiencia de unas decisiones supuestamente técnicas.

Si la sociedad organizada y no organizada llega a comprender que en el debate y la posibilidad de entendimiento se encuentra en juego la oportunidad para una vida mejor y más humana, es casi seguro que participará de buena gana, tal como se pide. Pero la invitación de la Comisión Nacional de Desarrollo no es suficiente para vencer el desencanto. Cerca de la tercera parte de los salvadoreños, según una encuesta del Instituto Universitario de Opinión Pública de julio de 1997, piensa que el país estará peor dentro de cinco años. Este pesimismo, justificado en alguna medida, genera el escepticismo que dificulta la participación de la ciudadanía en los movimientos sociales y los procesos electorales. Por consiguiente, la invitación debiera ir acompañada de algunos gestos inequívocos que subrayen el compromiso con el cambio social. El gobierno, los políticos y el sector privado debieran ser los primeros en mostrar su convencimiento sobre la necesidad de dicho cambio. No son buenas señales que, a la fecha, ninguno de estos sectores haya dado señales de haber asumido los principios y el horizonte de Bases para el plan de nación ni que los integrantes del grupo gestos se hayan distinguido por la defensa del bien común. Si el planteamiento no comienza a ser asumido pronto por los actores de la vida pública, corre el peligro de ser relegado al olvido, como los demás.

Así, pues, la participación de la sociedad no se materializará hasta que no se hayan desvanecido las dudas sobre la seriedad del compromiso con el cambio social por parte del poder económico y político establecido. Pero para ello, este poder primero debe convertirse al bien común y éste sólo se descubre desde el mal común y colocando en el centro a las mayorías poulares. Sólo entonces habrá disposición y se tendrá la capacidad mínima necesaria para aceptar el diagnóstico y discutir las propuestas. El poder establecido debe tomar la iniciativa y dar el ejemplo. Así como convocó a la comisión que redactó el documento base, también debiera impulsar de forma decidida la disposición para aceptar entrar en un proceso de cambio social.

Si esto no sucediera por la razón que fuera, la sociedad, al menos en teoría, podría retomar la iniciativa; pero, en la práctica, carece de la fuerza necesaria para impulsar una propuesta de gran envergadura, como ésta, en contra del poder establecido. Es paradójico que ahora se busque el apoyo de un movimiento social fuerte que no hace mucho se desarticuló, por temor a 
la oposición que seguramente haría al reajuste estructural. La experiencia muestra que la organización de la sociedad, aunque pueda ser molesta por cuestionante en algunos momentos, es imprescindible para el bien común.

Al no haber sido rechazado, en gran parte por su carácter abierto, pluralista $\mathrm{e}$ independiente, Bases para el plan de nación ha superado con éxito el primer peligro, pero le quedan otros. De momento, el más inminente parece ser el olvido o la irrelevancia. De todas maneras, la prueba definitiva vendrá cuando los puntos de vista hayan sido expresados, las diferencias sean insalvables y haya que tomar decisiones. Será más fácil que las organizaciones populares acepten las transformaciones propuestas, sobre todo si obtienen algunas ventajas palpables a corto plazo, a que lo hagan los grupos de poder, si consideran que los cambios amenazan sus intereses. La presión necesarià para forzar el proceso no podrá provenir de una sociedad pobremente organizada ni tampoco de un nacionalismo cuyo peso específico es mínimo cuando se trata de intereses materiales. Quizás sea más determinante sopesar las ventajas que el poder establecido podría obtener a mediano y largo plazo de una sociedad más estable.

la participación de la sociedad no se materializará

hasta que no se hayan desvanecido las dudas sobre la seriedad

del compromiso con el cambio social por parte del poder económico y político establecido.

Bases para un plan de nación plantea un desafío que debe ser asumido por todas las fuerzas sociales, en el entendido que ninguna de ellas tiene, por sí misma, ni la capacidad ni el poder para asegurar el bien de la sociedad salvadoreña. Por lo tanto, la buena disposición y el concurso de todas ellas son forzosamente necesarias. El Salvador se encuentra de nuevo ante una encrucijada histórica. Ante sí tiene la posibilidad para avanzar hacia unos cambios que permitan mejorar de forma sustancial el nivel y la calidad de vida de sus habitantes u optar por más pobreza e inseguridad social para todos.

San Salvador, 19 de febrero de 1998. 